\title{
Data Firme: The Media Revolution in the Amazonian Outskirts
}

\author{
Keywords \\ Participatory Media, Social Innovation, Theory of Change, Amazon, Informal Settlements.
}

What positive social impacts can academic practices bring to people's social vulnerability? Here, we try to answer this question by presenting the Data Firme, a Community-Engage Research from the Universidade Federal do Pará (UFPA), aiming to achieve social innovation into the civic media movements in the Terra Firme district. The project considers social innovation as the recognition and support from public authorities for innovative citizen practices, the recognition of cultural diversity, and the empowerment of people formerly socially excluded. Therefore, the civic media movements happening in the district had all the necessary characteristics to achieve this concept. Furthermore, the Terra Firme is a popular suburb built by informal occupations in flooded areas during the 1980s and 1990s. It is a "Near-Periphery" because it has precarious characteristics. It is next door to up-standard districts within the metropolitan region's center. Since its beginning, Terra Firme's residents have learned to deal with all kinds of challenges. From the site's floods and occupation on stilts to conflicts with authorities and high crime rates. However, after years of an incremental landfill, the neighborhood was consolidated and connected to the city. It made it possible to access better public and private services than in the most distant outskirts. Civic media networks flourished after the more significant availability of mobile communication services and the action of young inhabitants who study at UFPA. The civic media movements started in 2014, after a series of murders that victimized eleven suburbs' residents. Slaughters such as this has been typical in Belém's poor suburbs since the 1990s, where police officers and former colleagues assemble militias to control the neighborhoods where the State lacks presence. However, after the 2014's events, the youth started to use digital media to promote protests to produce content exposing the violence and bringing attention to the outskirts. Although up to 2017 they had few achievements, their activities reached academics, deputies, and cultural professionals. It made it possible to start the Data Firme in 2018, which had created a partnership with the community for two years. The project used the Theory of Change to base its action plan and used Design Thinking strategies to interact with the community. Thus, after the project, there were outputs and outcomes. The outputs are material productions, such as the web series "Nós na Tela," which rescue the district's history through its elders' memories and the district Social Cartography. The outcomes are the social impacts, like the "increase in the visibility of low-income," which we have data to confirm. Additionally, empirically speaking, it is possible to notice other impacts in "self-esteem" and "network construction." For instance, we notice a shift in the mainstream media framing for the neighborhood, using the community background to produce journalist material. Another example is the recent partnership between the State Government and Tela Firme, the leading Civic Media group. This partnership is a bottom-linked strategy to achieve the kind of Social Innovation we have looked for since the beginning. 